\title{
CRÓNICA DEL SEMINARIO DE LEY NATURAL Y PERSONA HUMANA
}

\author{
Débora Ranieri de Cechini
}

Universidad Católica Argentina, Buenos Aires, Argentina

Contacto: dranieri@uca.edu.ar

Para citar este texto:

Ranieri de Cechini, D. (2021). "Crónica del Seminario de Ley Natural y Persona Humana". Prudentia Iuris, N. 91, pp. 21-22 DOI: https://doi.org/10.46553/prudentia.91.2021.pp.21-22 
Desde 2019 se desarrolla en la Facultad de Derecho (UCA) un Seminario de Ley Natural y Persona Humana, coordinado por los profesores Siro De Martini y Débora Ranieri, junto a alumnos de los primeros años de la carrera que poseen interés en formarse e investigar cuestiones atinentes a los fundamentos del Derecho, la finalidad del orden jurídico, la relación con la moral y la ley natural. Participan también algunos profesores Adjuntos, Asistentes y Adscriptos del claustro académico.

El Seminario se desarrolla a partir de encuentros quincenales de dos horas de duración. En ellos, dos de los estudiantes exponen el texto previamente seleccionado que los demás participantes deben haber leído. El propósito de esta exposición no es tanto el de explicar el texto como el de hacer presente las diversas ideas y argumentos que contiene. A partir de allí, surgen naturalmente dudas, cuestionamientos, interrogantes que son planteados por cualquiera de los presentes y que suelen dar lugar a diversos análisis o discusiones. Tanto los estudiantes como los profesores más jóvenes pueden intervenir libremente en este camino dialéctico de búsqueda de la verdad.

Los coordinadores del Seminario intervienen para aclarar conceptos, ideas o referencias filosóficas que escapan al conocimiento de todos o algunos de los participantes. También, en ciertos casos, para hacer notar alguna dificultad que no ha sido planteada o algún argumento que pudiera agregarse a los ya expuestos. El mismo tema del Seminario lleva a una necesidad casi permanente de hacer referencia a problemas éticos de actualidad, por lo que es habitual que el camino que se recorre alterne la reflexión sobre los principios y sus conclusiones necesarias, y su a veces dificultosa encarnación concreta.

Durante el año 2020, el Seminario abordó el tema: "Derecho Natural y problemáticas contemporáneas", con encuentros cada 15 días, los miércoles de 13.00 a 14,30 en aula virtual de la Facultad de Derecho. Se realizó la lectura y análisis de "En busca de una ética universal: una nueva mirada sobre la ley natural” (Comisión Teológica Internacional, 2008). 